EDITED UNDER THE DIRECTION OF THE BOARD OF TRUSTEES.

PUBLISHED WEEKLY.

\begin{tabular}{|c|c|}
\hline Vol. XVI. & CHICAGO, \\
\hline \multicolumn{2}{|c|}{ ADDRESSES. } \\
\hline \multicolumn{2}{|c|}{ THE PRESIDEN'T'S ADDRESS. } \\
\hline $\begin{array}{l}\text { Delivered at the For } \\
\text { cal Associa }\end{array}$ & $\begin{array}{l}\text { ie American Medi- } \\
\text { ay } 5,1891 \text {. }\end{array}$ \\
\hline BY & \\
\hline
\end{tabular}

Ladies and Gentlemen: My heart swells with pride when I look over this vast assembly of the representatives of a profession, distinguished alike for its antiquity, its scientific attainments, and its usefulness; a profession which forms the true link between science and philanthropy.

You, gentlemen, as members of this Association, have been delegated by your local Associations, from every part of this Grand Republic, from the Kennebec to the Rio Grande, from orange groves and golden sands, from mountains clad in eternal snows, and valleys smiling in perpetual verdure, to represent them on this occasiou.

You are here with no selfish motives, nor purposes of self-aggrandizement, nor to excite or perpetuate sectional antipathies.

Indeed, as physicians you should recognize no section; with you there should be no East, no West, no North, no South. You are here solely for the promotion of science and for the good of the human race. You are here to maintain the honor and dignity of the profession and to hold aloft the flag of honorable medicine. You are here to lay your contributions, - the accumulations of your study and observation,- - upon a common altar for the common good ; to worship at the sacred shrine of medicine and to renew your fealty to the noble profession to which you have devoted your lives and linked your fortunes. You are here to exchange experiences with each other, to separate by discussion the grains of truth from the wordy chaff in which they may be hidden, to renew friendships and to weave more closely the bonds of professional brotherhood.

As physicians you have an almost superhuman mission to fill. Life, the greatest of human blessings, and health, the greatest stimulant to earthly enjoyment, are the issues with which you are called to deal.

The chief objects of your professional work are to preserve the one, and to procure the other. The goal of your ambition and desire is almost at the end of human capacity. It is your province as well as your earnest desire to know all the secrets of organization. You would have the formative crystal and germinal spot made transparent. You would enter the microscopic world and witness the wonders therein revealed. Indeed, you would, if it were possible, search into and unravel the very mysteries of the vital principle.

To this perfect knowledge you aspire.

It is doubtful if man's intellect, great as it is, can ever compass all that he so earnestly desires, yet by constant and faithful work he may approach nearer and nearer to its consummation.

He has before him rich and boundless fields for research, from which the eager and enthusiastic explorer may gather the richest prizes. To these fields the future generation of physicians will be attracted in the hope and belief that as man advances in knowledge and approaches nearer to the understanding of the perfect wisdom, which designed his physical organization and by which he is brought in relation with the world around him, he will be enabled to solve more and more of the difficult problems which have, for ages, baffled and perplexed him, and to elevate the profession of medicine to a position more nearly akin to that accorded to the exact sciences.

We live in an age of progress, and all the arts and sciences are advancing with gigantic strides. With the aid of steam and electricity time and space have been almost obliterated. The most distant parts of the world have been made neighbors. A fact developed or an important discovery made, is flashed in the shortest conceivable time to the most remote parts of the globe and given to the public without money and without price.

The science of medicine has kept pace with, if it has not outstripped all other sciences.

It has been completely revolutionized within our day. The microscope, chemical analysis, clinical observation and vivisection are carrying the medical mind with wonderful velocity in pursuit of knowledge, far beyond, indeed, the most sanguine conceptions of even a third of a century ago.

In every part of the habitable world blessed 
with the light of civilization, active, busy members of our profession endowed with high culture and incited by the noblest resolves are enthusiastically engaged in unravelling the mysteries of disease and seeking the means and methods of treatment for the mitigation and relief of suffering and the prolongation of life.

That the full benefit of the labors of American physicians might be attained and utilized, it was essential that the members of the profession scattered over an area of country of almost inconceivable extent, should be brought into associated action, - should be organized into a body by whose annual discussion an exciting, vivifying and healthful infiuence might be exerted over the length and breadth of the land, until a correct and noble sentiment had been engendered in the bosom of every member of the profession.

Through the brilliant genius and indomitable energy of cne who is known as the "Father of the Association," this grand body was formed and has ever been sustained and fostered by his parental solicitude, in which he has been nobly assisted by the cordial coöperation of his brethren. More than a generation has passed since its organization, and many of the master spirits which were present and assisted in the inauguration of the enterprise have joined the silent majority, leaving it as a precious heritage to their successors, who should be actuated by the same spirit which inspired those who bad preceded them, and with the same energy and zeal endeavor to manage the bigh trast with an eye single to the honor and glory of the profession.

A few of those who assisted in its organization in 1847 , weighed down with honors and years, still make annual pilgrimages to this Medical Mecca and by their presence and counsel add increased interest to its meetings.

Chiefest among these is Nathan Smith Davis, to whom, more than any other, is due the credit of establishing and perpetuating this National Association-venerable, distinguished, renowned, may he he long spared to counsel and assist in the deliberations of the body!

The purposes of those who organized the Association were to protect and promote the interests of the American Medical profession, to maintain its honor and respectability, to advance its knowledge and to extend its usefulness.

That these desirable objects have been accomplished to a very great extent is a matter of history.

Through its moral influence it has united the great mass of physicians from Maine to Texas, and from the Atlantic to the Pacific in the bonds of fellowship, many of whom at great sacrifice of personal comfort and pecuniary interest, come to the annual meetings with hearty fraternal greeting for each other, and who, becoming touched as with a living coal of fire, renew their vorws of faithfulness and loyalty to the cause in which they are engaged, and form the high and noble resolve to devote their time, talent and lives with still greater assiduity to their chosen profession.

If the Association had done nothing more than to have accomplished this unification of the Medical profession, it would have performed a service entitling it to an imperishable name. It has, however, been an active and powerful agent in the promotion of medical science and in the dissemination of useful knowledge. It has excited a spirit of improvement among the masses of the profession which nothing can stay.

Another great benefit conferred by the Association was the establishment of an esprit de corps in the profession, by the preparation and adoption of a Code of Ethics which comprises the great principles of truth, honor and justice, in regulating the relations of physicians to each other, to their patients and to the public. It should be and is the written law clearly defined and of acknowledged force and effect that prevails from one end of the country to the other. It forms an impassable barrier between the sheep and the goats, the clean and the unclean, the physician and the charlatan.

The strict observance of the Code has done more than anything else to maintain harmony in the profession and to elevate it in the public estimation. It embodies the true spirit of the Golden Rule,- "Do unto others as you would have others do unto you."

Every one who enters the profession should be provided with a copy of the Code and should make it the guide of his medical life. It will serve as a talisman to the young physician, and will be the best safe-guard against the snares and pitfalls which environ his pathway in his early professional life.

It would seem that every honorable and high minded member of the profession would be willing to endorse and be controlled in his intercourse with his medical brethren and the public by every article of the Code.

It is, however, to be regretted that there are some, who undoubtedly possess high order of talents, and are justly distinguished, who have an utter repugnance to the observance of certain parts of the Code and hold themselves aloof from the Association in consequence.

They, probably are as proud of our noble profession as we, and are equally as anxious for the advancement of its interests, but can they conscientiously affirm that the motives by which they are influenced are pure and unselfish? And should they, a small minority, put their opinion against the unbiased and unselfish judgment of the wisest and most experienced in the profession? And when, too, nine-tenths of that profession endorse 
and are guided in their actions by the spirit and letter of the Code?

The chief object-indeed the fundamental idea of those who originated the Association was the improvement of the American system of medical education and the elevation of the standard of requirements for the professional degree. Never was there a greater expenditure of effort, illuminated with genius and learning, to accomplish these two great objects. Never was there more eloquent and philosophical reports to any organization than those presented by the committees appointed year after year, to this body; yet it seemed, after all efforts in that direction, as far from fruition as at its initial meeting. The resolutions proposed and adopted from time to time, were sufficiently pointed and admirably adapted to the end in view, but, unfortunately the Association had no legislative authority or power to enforce its enactments, and its moral suasion and influence was not great enough to move the college to accept their counsel.

In 1850 the medical colleges were invoked to meet and correct the great evils of the prevalent plan of teaching in this country, but they did not respond to the appeal. Since then, on various occasions, delegates from the medical colleges have met and discussed plans for the advancement of medical education but have failed, from want of coöperation and united action, to make the desired changes.

The idea of making such changes in the medical education of our youths in a country so diversified and of such extent, in a few years, was probably Utopian. Such radical and lasting changes can only be effected by the slow work of time. There has, however, been a gradual elevation in the standard of education, fully equal to the progress of the country in every other department of human learning.

To those of us who entered upon our medical studies twenty, thirty, or forty years ago it will be gratifying to visit any well organized medical college and witness the many improvements and the increased facilities for the instruction of its pupils. The extended curriculum of instruction, both in the didactic and clinical departments, the patient and painstaking work in the laboratories of Chemistry, Physiology, Pathology and experimental Therapeutics; the special instruction in the department of Surgery, Obstetrics and Gynecology and Ophthalmology; the resources afforded by hospitals and dispensaries, and the admirable arrangement for the prosecution of Practical Anatomy in the dissecting room, all attest the wonderful progress and advancement made in medical teaching since our pupilage.

I am ready to maintain that the advantages and facilities for medical instruction in our country even at the present time are quite equal to those of any other, and that our medical colleges have produced as able, learned and successful practitioners as ever graduated from other institutions, and while I am willing to admit that our transatlantic brothers have excelled us in experimental work. we excel in all practical departments of medicine. Chassaignac, the eminent Parisian surgeon, exclaimed a few years since, that America held the scepter of the Surgical world; and more recently Virchow, President of the late International Medical Congress, said, "The American Medical world to-day excels in Surgery, Midwifery and Dentistry."

What American physician is not overwhelmed with thankfulness when he remembers the pain and anguish which has been prevented through the great boon of anæsthesia, which in the providence of God was given to our country; who will ever tire of hearing of the great blessing conferred on suffering women by the genius and skill of McDowell, or of the marvellous changes made in Gynecological Surgery by the prolific brain and cunning hand of Sims.

Had America done nothing else than contribute these gifts to the world it would have been made famous for all time to come.

The great advance made in our medical education has been undoubtedly due to the frequent and very able discussions which have been held on the subject in this Association, and to the eloquent and philosophical reports of committees of education which have been so often appointed, and apparently with so little effect,-but the seed so wisely sown in the organization of this body have germinated and are now of hardy growth, and it is hoped in the near future will attain maturity and yield a harvest of abundant and perfect fruit.

The professional public have been aroused on the subject of a higher and better education than has been furnished by the old system, even, as improved by modern advancement. This professional sentiment has extended to medical teachers, and I believe that a majority of American medical colleges are now ready to acquiesce in the demands of the profession for a higher education, and that they will execute to the fullest extent the wishes of the Medical College Association as expressed at the meeting in Nashville last year. And when the medical colleges shall have entered upon the higher education which they have determined to do, the American Medical Association will have cause to congratulate itself in the accomplishment of the chief object of its organization.

The success of the Association in these and other purposes has been very great, even beyond the expectations of its most sanguine friends. "As a social and professional reunion of kindred spirits and great minds, its memories afford perennial 
delight. It has given impetus to the progress of polity and science, it exercises moral suasion rather than authority, it has brought together a bright constellation of intellect, cemented the bonds of friendship among good men and true, and has formed a luminous track of light in the -firmament of the Esculapian heavens throughout the length and breadth of the land." It has passed safely through the perils of infancy, avoided the errors of youth, has entered upon the full estate of manhood, and now occupies an advanced position in the deliberative assemblies of the world. Constituted of delegates coming from every part of the country and representing every interest of the profession, it is really a great National Congress; it is the only legislative body of the profession which can regulate the action of its mem. bers and harmonize their conflicting interests; and it is full time that it should assume the power of legislating for the whole American profession and demand that its enactments be observed. That this power may be attained and exerted beneficially, greater efforts should be made to bring into the Association every prominent and influential member of the medical profession, especially those who have thought proper to alienate themselves from its deliberations. Let us ask them in the true spirit of conciliation to throw aside their narrow prejudices and renew their allegiance to the Association. Let us relegate all the asperities of the past to oblivion and remove the unpleasant feelings which have existed for the past four or five years, to the end that the medical profession of America may be, "Though distinct like the billows, yet one like the sea ;" that it may be truthfully exclaimed, "Behold how good and how pleasant for brethren to dwell together in unity." Then, encouraged by the knowledge of the moral power of the Association, let us not be satisfied with what has been done in the past, but press on in the good work we have undertaken, toward perfection, securing as much beauty and finish for the body as is compatible with the imperfections of the human understanding.

Now that the College Association has adopted all the requirements for improved medical education, which the Association has been so long urging, and for which, in fact, it was established, it is eminently proper, and I would urgently press its importance on the members, to pass a resolution, that after the changes contemplated have gone into effect, no medical man who has received a degree from a college which has not adopted the improved method of teaching, and no professor nor attaché of such college shall be eligible as delegates or members of this Association.

This great moral support is due those colleges which so heartily took up the burden that the Association has carried for nearly half a century, and I hope it will be cheerfully accorded them.

It is a well known fact that a very large proportion of the members of this body at each session, come from the vicinity of the place of meeting, many of whom have never been present at the sessions before, and are ignorant of the parlia. mentary usages of the body, or entirely indifferent what business is before it, or how it is disposed of. So that a few only of its members shape and conduct the entire business. Indeed, the transaction of routine business of the Association is uninteresting ard irksome. Sometimes in the discussion unpleasant feelings are engendered and animosities formed which interfere materially with the harmony necessary for the welfare and usefulness of the Association. I would therefore respectfully suggest, that all business matters of the Association, should be referred without discussion or comment, to an executive committee composed of two members to be appointed by every State Society in affiliation with this body, who, after mature deliberation, shall report them back to be adopted or rejected, as the Association may determine; and that the morning session, which has been heretofore consumed in the transaction of ordinary business, shall be occupied in the discussion of living, burning questions selected by the business or the nominating committee, and that members especially qualified to discuss the questions chosen, shall be selected a year in advance, that they may be thoroughly prepared for the duties assigned them. Such discussion will be greatly conducive to the advancement of medical science and will attract a great number of the best medical men who are not interested in the routine business of the Association, and who are consequently never present at the meetings.

To still further promote science and add to the interest of this body, I would suggest that prize essays provided for in the organization, and for so long a time ignored, shall again receive the attention they deserve. I feel sure that it is the sincere desire of every member of the Association that it progressively improves in the quality of the work it presents to the profession from year to year. There is, in my opinion, no exercise which will add more to the interest of the Association, or do more to promote science, than the presentation of essays which will be offered in competition for suitable prizes.

In this connection it may be well to call the attention of the Association to the fact, that original research and experimental investigation have not received the attention from American physicians, which their importance demands. Living as we do, in a comparatively new country, our energies have been directed to the promotion 
of the practical, and more directly, useful departments of the profession than to the minute investigation of scientific subjects; and our government, while the most liberal and best under the sun, has never seemed to comprehend that the cause of science, especially medical science, would be greatly advanced, and its own honor proportionately increased, by the establishment of schools for original investigation and experimental re search. It Las not kept pace with the other enlightened governments in scientific enterprises. It is hardly to be expected, however, that in the rapidly changing political dynasties, the atten tion of our legislators could in the near future be directed to the advancement of pure science. This must, for the present, at least, be left to the progressive spirit which animates our universities, and to pritate laboratories which are being established in different sections of the country. Would it not be advisable for the Association to establish a Section of Experimental Research, to which young and enthusiastic devotees might be encouraged to make and repeat experiments in all the departments of medicine? It would certainly form a very interesting and useful Section, and would tend to advance science and add greatly to the interest of the Association.

It was a happy conception of one of our most distinguished presidents to make the establishment of an Association Journal the burden of his inaugural address, and so powerfully did he impress its importance upon the minds of the members of the Association, that a committee was at once appointed to take into consideration his suggestion, with the result that a weekly Journal was established to take the place of the annual volume of Transactions. That the change has been a valuable one none will deny. It has asserted and maintained the honor, dignity and power of the medical profession as a factor in civil life; it has tended to enlighten and strengthen the profession, and to lead it in the proper direction. Its design has been to represent in the broadest sense the true status and progress made in this country and to give expression to the thoughts, purposes, and will of American physicians. It has in the short period of its existence given evidence of its power in the advancement of its purposes. Yet it must be acknowledged, notwithstanding the great learning and untiring energy of its editors, together with the faithful coopperation of its trustees, that it has never attained the ideal excellence which should characterize the organ of this great body of physicians. It may require years to bring it to the desired standard, and it should be determined here to-day, that every effort shall be made to advance it to the highest standard. To effect so desirable an object it is necessary to make provision for an ample annual income.
Nothing less than from seventy-five to one hundred thousand dollars should be considered ample. To many, this sum may seem chimerical, but it is not. If every member of this body would constitute himself a live, active agent to solicit subscriptions from his brother physicians living in his vicinity, and to assure himself that TyE JOURNAL is on the table of every doctor within his reach; and if to this is added the income which may be derived from legitimate and properly selected advertisements, the necessary fund will be assured.

Next in importance to finance, is the selection of an editor, able, learned, highly educated, with ample editorial tact and business qualifications, who will devote all of his time and talent to his editorial duties. He should be empowered to spend money liberally in obtaining scientific material, original communications, translations and reviews from every part of the world. He should have absolute control in the selection of matter for THE JOURNAL; he should manage THE JOURNAL boldly, vigorously and with an eye single to the honor and glory of the profession.

To such an editor a salary should be given which would make him independent in a pecun. iary point of view. Not less, I would suggest, than ten or fifteen thousand dollars should be paid to him annually. Then, with elegant paper, perfect typography and attractive binding, THE JoURNAL will add lustre to the Association and honor to the profession.

The necessary fund, which can be easily raised by proper exertion, will not only sustain THE JOURNAL in the best style, but will afford a sum in addition which can be used in many ways to the advantage of the Association.

The future location of THE JOURNAL is a matter of such importance as to require our careful consideration and mature deliberation. Its weal or woe may depend on the action of this meeting.

At an extraordinary session of the Board of Trustees of THE JourNaL called to meet in Washington city last November, it was determined to submit the question of its removal from Chicago to Washington, to the action of the members of this session.

I would beg the delegates and members of the Association to consider well every side of this question before they commit themselves to a vote, and not act too hastily in the matter. THE JoURNAL has now had its home in Chicago for eight years. Its development and growth has been wonderfully rapid. It has already become the peer of any of the great weeklies of the country and if properly sustained by the profession and wisely and energetically conducted by its managers, it will become the recipient of the best thought of our own country and be the worthy exponent of the American profession. It is free from debt 
and has funds sufficient to close the financial year and still leave a satisfactory balance in the treasury. It has been proven that it can be more economically published in Chicago than in Washington. The Board of Trustees several years since solicited and obtained estimates from two or more publishing houses in Philadelphia, Washington, New York and Chicago. These estimates were uniformly highest in Washington and lowest in Chicago.

Chicago is a geographical and railroad centre not excelled in facilities for rapid mail distribution. It is also a great medical and surgical centre and can place at the disposal of THE JOURNAL a wealth of resource, second to no other city in the Union. It is the best place for advertisers to reach the profession in the Mississippi Valley and the great North-west, and if THE JournaI should be removed to Washington, it will lose many very lucrative advertisements and will be brought into direct and sharp competition with six important weekly journals, several sustained by large and influential book houses. which occupy the field between Washington and Boston.

Washington is in no sense an important scientific, educational or professional centre; but it is the great centre of American politics, to which everything is made subordinate; and it would be impossible if THE JOURNAL should be published here, to prevent its becoming contaminated by the political air, with which it would be surrounded. Washington has never been a healthy locality for medical journals, for every journal which has been published within its boundaries, has died early from inanition. I do not think that it is a better locality than Chicago that is wanting, but a better Journal than we have.

Let us then as members of a profession engaged in the most beneficent and humane calling known to man, in the language of the immortal Jackson, swear "by the ETERNAL" that THE JOURNAL OF THE AMERICAN MEdical Association, wherever it may be located, shall be made and kept equal in excellence with any journal published in the world.

It is now time to enter upon the duties which have called us together. Let us endeavor to discharge them in a spirit of conciliation and justice. Let us act with such prudence and judgment in this meeting as will tend to unite more closely the members of this great National family. Let us not forget how rich an heritage has been bequeathed to us by our predecessors which we should make more valuable and transmit to posterity. Let us indulge the hope that our labors during the present session will not only sustain the advance already made in medical science, but will carry us still further onward in the great road of progress.

\section{THE ADDRESS ON SURGERY.}

Delivered at the Forly-second Annual Meeting of the American Medical Association, held at W'ashington, D.C., May', M'HI. BY JOSEPH M. MATHEWS,

OF LOCISVILLE, KY

I am familiar with the fact that it is expected that the general address on surgery read to this Association shall be a résumé of the advances made in each and every department of the science and art of surgery, since the previous meeting. To have gone over this entire field would have consumed more of your valuable time than you would like to grant, and involved a task too burdensome for me to undertake. I, therefore, determined to select some single subject for my address. I was then confronted by the fact that every single subject of importance would be fully discussed in the section on surgery; hence I was embarassed in selecting one, for the reason that I wished to edify rather than fatigue you. This, then, was the rub. Having confined myself for fifteen years to a special line of practice, it occurred to me that it would be best to select some subject relating thereto, and give my individual opinion and experience in regard to it. Then, too, I had the consolation of belic ving that no paper of a similar topic would be read before the Association. I have, therefore, selected as my subject,

STRICTURE OF THE RLCTUM-ITS ETIOLOGY, PA-

THOLOGY, SYMP'TOMOLOGY, DIAGNOSIS AND TREATMENT.

I realize, in discussing this subject, I shall take positions contrary to the accepted teachings of the day, but I shall not beg for pardon for so doing. I take it that the one great object of the meetings of this Association is to elucidate and discuss subjects that are in doubt, those that are mooted, not admitted. The caption of my address may sound homely, but the importance of it as a surgical subject should commend the respect and attention of every surgeon here. Its frequency, its terrors, and its dangers, appeal to us for relief.

Etiology.-The following classification of the varieties of stricture of the rectum is given by Dr. Kelsey. I believe that for my purpose it is the best classification, as it embraces the varieties as given and agreed to by many different authors. Congenital:

I. Complete,

2. Nartial.

Acquired:

I. Spasm. a. Dysenteric.

2. Pressure from without. $b$. Tubercular.

3. Non-venereal. $c$. Inflammatory. $d$. Traumatic.

4. Venereal. $a$. Ulceration (either chancroidal, secondary or tertiary.)

5. Cancer. $b$. Due to unnatural vice. $c$. Neoplastic (gummata, anorectal syphiloma.)

The first great division, it will be noticed, is congenital and acquired stricture. In writing of, or dealing with stricture, the idea intended to be conveyed is of a pathological change in tissues, 